\title{
Occupational Radiation Dosimetry Assessment Using an Automated Infusion Device for Positron-Emitting Radiotracers
}

\author{
A. Robert Schleipman ${ }^{1}$ and Victor H. Gerbaudo ${ }^{2}$ \\ ${ }^{1}$ Department of Health Physics and Radiopharmacology, Brigham and Women's Hospital, Boston, Massachusetts; \\ and ${ }^{2}$ Division of Nuclear Medicine and Molecular Imaging, Brigham and Women's Hospital, Department of Radiology, \\ Harvard Medical School, Boston, Massachusetts
}

Handling and administration of radiopharmaceuticals are a key contributor to staff radiation dose. Shielded automated infusion devices potentially standardize and reduce radiation exposure during procedures. However, loading the devices adds incremental radiation exposure, which may mitigate dose savings. We measured radiation doses from the loading and use of an automated infusion device and compared these with those from manual injection of ${ }^{18} \mathrm{~F}$ radiotracers. Methods: Adult patients were administered ${ }^{18} \mathrm{~F}-\mathrm{FDG}$ or ${ }^{18} \mathrm{~F}-\mathrm{FLT}$ before 3-dimensional PET whole-body or brain imaging, respectively. Radioactivity amounts from manual injections performed with protective syringe shields and vial holders were measured by a standard dose calibrator before and after injection. Automated infusions were performed using the shielded infusion device. Staff wore electronic dosimeters at the wrist and trunk. Electronic dosimeters were also worn while multidose ${ }^{18} \mathrm{~F}$ FDG vials were loaded and unloaded. For each task, background radiation was determined and subtracted from the electronic dosimeter values. Results: Twenty-seven manually injected unit doses yielded a mean administered dose to patients of $480.7 \pm 66.2 \mathrm{MBq}(12.99 \pm 1.79 \mathrm{mCi})$, compared with $431.9 \pm$ $22.7 \mathrm{MBq}(11.67 \pm 0.61 \mathrm{mCi})$ in 34 automated injections. The mean difference was statistically significant. To control for this difference, results were expressed as a standardized dose per unit of activity. With the automated infusion device, the mean extremity dose per injection was $0.003 \pm 0.002$ $\mu \mathrm{Sv} / \mathrm{MBq}$, compared with $0.026 \pm 0.017 \mu \mathrm{Sv} / \mathrm{MBq}$ with manual injections. Mean body dose per procedure with automated infusion was $0.001 \mu \mathrm{Sv} / \mathrm{MBq}$, versus $0.011 \mu \mathrm{Sv} / \mathrm{MBq}$ with manual injection $(P<0.001)$. The changing of bulk ${ }^{18} \mathrm{~F}-$ FDG vials in 37 procedures added a mean dose per vial change of $0.89 \pm 1.3 \mu \mathrm{Sv}$ to the extremities and $0.47 \pm 2.0$ $\mu \mathrm{S} v$ to the body. Conclusion: The use of a shielded automatic infusion device in a clinical PET setting resulted in an approximately 10 -fold decrease in staff extremity and body doses during the administration of ${ }^{18} \mathrm{~F}$-labeled radiopharmaceuticals. Loading and unloading bulk vials of radiotracer did not significantly offset these dose savings.

\footnotetext{
Received Mar. 16, 2012; revision accepted May 18, 2012.

For correspondence or reprints contact: Robert Schleipman, Department of Health Physics and Radiopharmacology, Brigham and Women's Hospital, 75 Francis St., Boston MA 02115.

E-mail: aschleipman@partners.org

Published online Sep. 27, 2012.

COPYRIGHT @ 2012 by the Society of Nuclear Medicine and Molecular Imaging, Inc.
}

Key Words: ${ }^{18}$ F-FDG; ALARA; automated infusion; occupational radiation dose

J Nucl Med Technol 2012; 40:244-248

DOI: $10.2967 /$ jnmt.112.106070

$\mathbf{R}$ educing radiation exposure to patients, nuclear medicine staff, and others is a common goal of professionals in radiation protection and nuclear medicine. Potential increases in both medical and occupational radiation exposure have become a more urgent and persistent issue with the increasing dissemination of PET imaging, which uses higher-photon-yield radiopharmaceuticals such as ${ }^{18} \mathrm{~F}-\mathrm{FDG}$ (1-3). Task-based analyses often point to the handling and administration of radioactive materials as a key contributor to increased dose to staff (4-7).

Shielded automated infusion devices have recently been introduced, allowing for subsequent reductions in radiation exposure to staff during patient dosing procedures (8-10). These dose reductions are possible for several reasons. The first is the increased distance of operators from the patient during the injection; that is, the technologist or physician can simultaneously monitor the patient and injection from a distance of several meters. Second, these devices contain varying amounts of lead or tungsten shielding. However, the loading of bulk injectate vials that may contain up to $25 \mathrm{GBq}$ of ${ }^{18} \mathrm{~F}-\mathrm{FDG}$, as well as the maintenance or troubleshooting of the devices, potentially adds incremental radiation exposure not incurred by individual syringe injections using the manual technique. Additional exposure is particularly likely when there are loading difficulties associated with air in the line or crimped tubing or when general unfamiliarity with the device arises. Therefore, it remains unclear how these devices will fully affect clinical throughput and the cumulative radiation dose burden to staff. In addition, improved precision of administered radiopharmaceuticals, leading to less variation in patient dose, should be achievable with automated devices.

This investigation was designed to measure and compare various task-based radiation doses from both automated infusion and manual injection protocols of ${ }^{18} \mathrm{~F}$-labeled radio- 
pharmaceuticals in a clinical setting. Both administered patient doses and occupational exposures and doses were examined in a protocol preapproved by the institutional review board of the hospital.

\section{MATERIALS AND METHODS}

Adult patients were administered ${ }^{18} \mathrm{~F}$-FDG or ${ }^{18} \mathrm{~F}$-FLT before 3-dimensional PET whole-body or brain imaging, respectively. Radioactivity amounts from manual injections performed with protective syringe shields and vial holders were measured by a standard dose calibrator (CRC-25R; Capintec, Inc.) before and after injection. Automated infusions were performed using the Intego (Medrad) shielded injection device (Fig. 1). The licensed nuclear medicine technologists had an average of $8.3 \mathrm{y}$ (range, 3-20 y) of postgraduate experience. All had undergone onsite training with the automated infusion device, which had been in service approximately 11 mo before initiation of this study. Staff wore electronic personal dosimeters (MY DOSE, PDM-112; Aloka Co., Ltd.) at the wrist and trunk during syringe preparation, injection, and measurement of residual activity. These silicon semiconductor dosimeters display doses between $1.0 \mu \mathrm{Sv}$ and $10.0 \mathrm{~Sv}(0.1 \mathrm{mrem}-1,000 \mathrm{rem})$ and respond to a $\gamma$-energy range from $40 \mathrm{keV}$ to $1.5 \mathrm{MeV}$. Depending on patient schedule and radiopharmaceutical production methods, bulk vial changes within the automated infusion device were performed 1 or 2 times per day. Staff doses were also measured during loading of multidose ${ }^{18} \mathrm{~F}-\mathrm{FDG}$ vials into the device, as well as during removal of decayed vials from the device. For both injection and vial-handling tasks, background radiation values were predetermined with a pressurized ion chamber (Inovision 451P; Inovision Radiation Measurements) and a traceable timer (Fisher Scientific) and subtracted from the electronic dosimeter dose value. The exposure rate in $\mu \mathrm{R} / \mathrm{h}$ was converted to $\mu \mathrm{Sv} / \mathrm{h}$ and multiplied by time increment-for example, room background rate $=54 \mu \mathrm{R} / \mathrm{h} \times$ injection time of $3 \min 48 \mathrm{~s}=54 \mu \mathrm{R} / \mathrm{h} \times 0.063 \mathrm{~h}=3.43 \mu \mathrm{R}=0.034 \mu \mathrm{Sv}$. A single observer used a dose measurement recording worksheet for each case (Fig. 2). Occupational doses to both extremity and whole body were tabulated and analyzed using Excel (Microsoft). Descriptive, parametric, and nonparametric statistics, when appropriate, were determined and analyzed using SPSS software, version 18.0 (SPSS Inc.).

\section{RESULTS}

\section{Administered Doses}

Manual drawing up and dispensing of the prescribed radiopharmaceutical using unit doses $(n=27)$ yielded a mean administered dose to patients of $480.7 \pm 66.2 \mathrm{MBq}$ (12.99 \pm $1.79 \mathrm{mCi}$ ). The infusions using the automated injection device $(n=34)$ delivered a mean administered dose to patients of $431.9 \pm 22.7 \mathrm{MBq}(11.67 \pm 0.61 \mathrm{mCi})$ (Table 1$)$. When compared with the automated infusions, the manual technique delivered a wider dispersion of the administered dose, with increased SE (Table 2). Furthermore, the mean difference of $48.8 \mathrm{MBq}(1.32 \mathrm{mCi})$ between patient doses was statistically significant by the 2-tailed $t$ test $(\alpha=0.05, \mathrm{t}=$ 4.02, $P<0.001$ ). Intuitively, technologist dose would be lower using the technique that administered lower doses, that

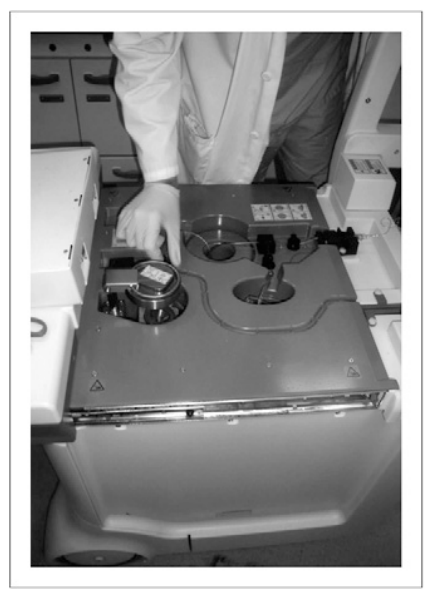

FIGURE 1. The Intego (Medrad) shielded injection device. is, the automated system. To correct for this error, the results were normalized using the following metric:

Operator dose per administered unit of radiopharmaceutical ( $\mu \mathrm{Sv} / \mathrm{MBq})$.

This then normalizes the results, allowing a comparison that is independent of the administered dose, and also permits comparisons across other cited works within the literature.

\section{Background Radiation}

Background exposure rates throughout were highly variable, ranging from 0.02 to $2.80 \mu \mathrm{Sv} / \mathrm{h}(2.0-280 \mu \mathrm{rem} / \mathrm{h})$. The actual task times in minutes varied as follows: manual

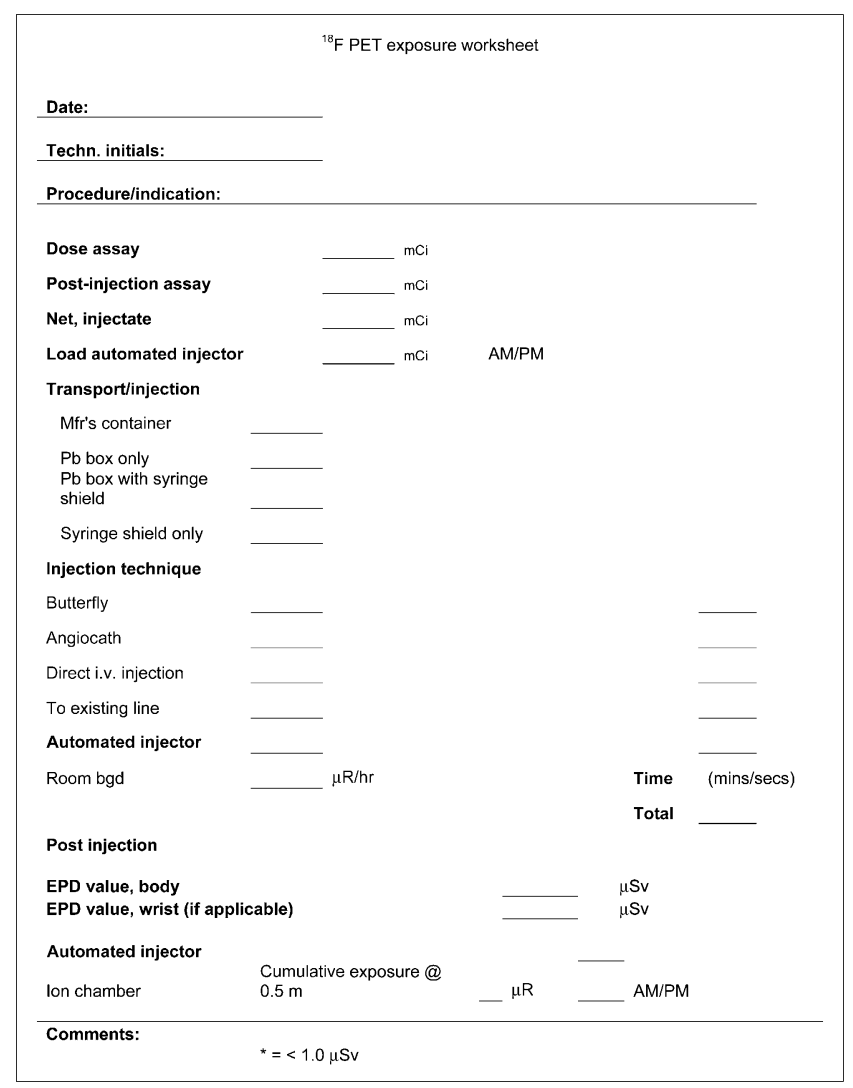

FIGURE 2. Worksheet for recording dose measurements. 


\begin{tabular}{|c|c|c|c|c|c|}
\hline \multicolumn{3}{|c|}{ Automated injection } & \multicolumn{3}{|c|}{ Manual injection } \\
\hline \multirow[b]{2}{*}{ Administered dose (MBq) } & \multicolumn{2}{|c|}{$\begin{array}{c}\text { Background- } \\
\text { corrected dose }(\mu S v)\end{array}$} & \multirow[b]{2}{*}{ Administered dose (MBq) } & \multicolumn{2}{|c|}{$\begin{array}{c}\text { Background- } \\
\text { corrected dose }(\mu \mathrm{Sv})\end{array}$} \\
\hline & Body & Wrist & & Body & Wrist \\
\hline 443.6 & 0 & 0 & 472.1 & 4 & 14 \\
\hline 357.1 & 0 & 1 & 405.5 & 4 & 3 \\
\hline 449.9 & $\mathrm{n} / \mathrm{r}$ & 2 & 609.8 & 4 & 5 \\
\hline 434.8 & 2 & 2 & 488 & 8 & 4 \\
\hline 436.2 & 0 & 0 & 494.3 & 5 & 14 \\
\hline 437.7 & 0 & 1 & 435.9 & 4 & 5 \\
\hline 442.9 & 1 & 2 & 431.8 & NR & 5 \\
\hline 434.8 & 1 & 2 & 589.4 & 4 & 11 \\
\hline 443.3 & 1 & 1 & 516.2 & 6 & NR \\
\hline 432.9 & 2 & 3 & 419.2 & 2 & 10 \\
\hline 446.2 & 1 & 1 & 399.6 & 5 & NR \\
\hline 444.7 & 0 & 2 & 428.1 & 8 & 24 \\
\hline 445.9 & 1 & 0 & 477.3 & 4 & 18 \\
\hline 434.8 & 2 & 3 & 451.4 & 9 & 19 \\
\hline 440.7 & 1 & 2 & 481.4 & 5 & 7 \\
\hline 365.2 & 1 & 1 & 478.8 & 4 & 15 \\
\hline 432.2 & 0 & 1 & 347.1 & 5 & 26 \\
\hline 434.8 & 0 & 0 & 458.8 & 2 & 2 \\
\hline 363.3 & 0 & 1 & 577.2 & 10 & 16 \\
\hline 436.2 & 1 & 1 & 624.9 & 3 & 8 \\
\hline 445.1 & 0 & 0 & 485.1 & 9 & 14 \\
\hline 440.3 & 0 & 1 & 445.5 & 5 & 16 \\
\hline 443.3 & 1 & 2 & 428.1 & 6 & 10 \\
\hline 432.9 & 1 & 0 & 559.8 & NR & 9 \\
\hline 438.5 & 1 & 0 & 504.7 & 3 & 9 \\
\hline 434.4 & 0 & 1 & 468.4 & 7 & 24 \\
\hline 433.3 & 0 & 0 & 501.7 & 5 & 20 \\
\hline 428.8 & 0 & 1 & & & \\
\hline 437.7 & 1 & 1 & & & \\
\hline 432.9 & 0 & 0 & & & \\
\hline 439.2 & 0 & 1 & & & \\
\hline 444.4 & 1 & 1 & & & \\
\hline 439.2 & 1 & 1 & & & \\
\hline 437.3 & 0 & 1 & & & \\
\hline
\end{tabular}

injection $=3: 08 \pm 0: 59$; automated injection $=3: 36 \pm 1: 50$; change in/out vial $=4: 04 \pm 1: 52$.

Multiplying task times by background rate yielded an average total background for all tasks of $0.013 \pm 0.02 \mu \mathrm{Sv}$ $(1.3 \pm 2.1 \mu \mathrm{rem})$.

\section{Operator Dose}

The operator dose results were determined from approximately 60 patient injections. No outlier values were censored from the data, though occasionally an electronic dosimeter was unavailable.

For extremity dose related to preparation and administration of radiopharmaceutical, the normalized dose to staff from the automated injections $(n=34)$ was $0.003 \pm 0.002$ $\mu \mathrm{Sv} / \mathrm{MBq}(11.1 \pm 7.4 \mu \mathrm{rem} / \mathrm{mCi})$. Manual preparation and injection technique $(n=25)$ yielded an extremity dose of $0.026 \pm 0.017 \mu \mathrm{Sv} / \mathrm{MBq}(96.2 \pm 62.9 \mu \mathrm{rem} / \mathrm{mCi})$ (Fig. 3).
The body dose to staff from the automated infusion $(n=$ 33) was $0.001 \pm 0.002 \mu \mathrm{Sv} / \mathrm{MBq}(3.7 \pm 7.4 \mu \mathrm{rem} / \mathrm{mCi})$, whereas manual techniques $(n=25)$ yielded a body dose of $0.011 \pm 0.005 \mu \mathrm{Sv} / \mathrm{MBq}(40.7 \pm 18.5 \mu \mathrm{rem} / \mathrm{mCi})$ (Fig. 4).

TABLE 2

Administered Doses (Injectate) by Method

\begin{tabular}{lcrrrr}
\hline & \multicolumn{2}{c}{ Automated } & & \multicolumn{2}{c}{ Manual } \\
\cline { 2 - 3 } \cline { 5 - 6 } Parameter & $\mathrm{MBq}$ & $\mathrm{mCi}$ & & $\mathrm{MBq}$ & $\mathrm{mCi}$ \\
\hline Mean & 431.89 & 11.67 & & 480.74 & 12.99 \\
SD & 22.68 & 0.61 & & 66.22 & 1.79 \\
Minimum & 357.05 & 9.65 & & 347.06 & 9.38 \\
Maximum & 449.92 & 12.16 & & 624.93 & 16.89 \\
SE & 3.89 & & & 12.74 & \\
$N$ & 34 & & 27 & \\
\hline
\end{tabular}




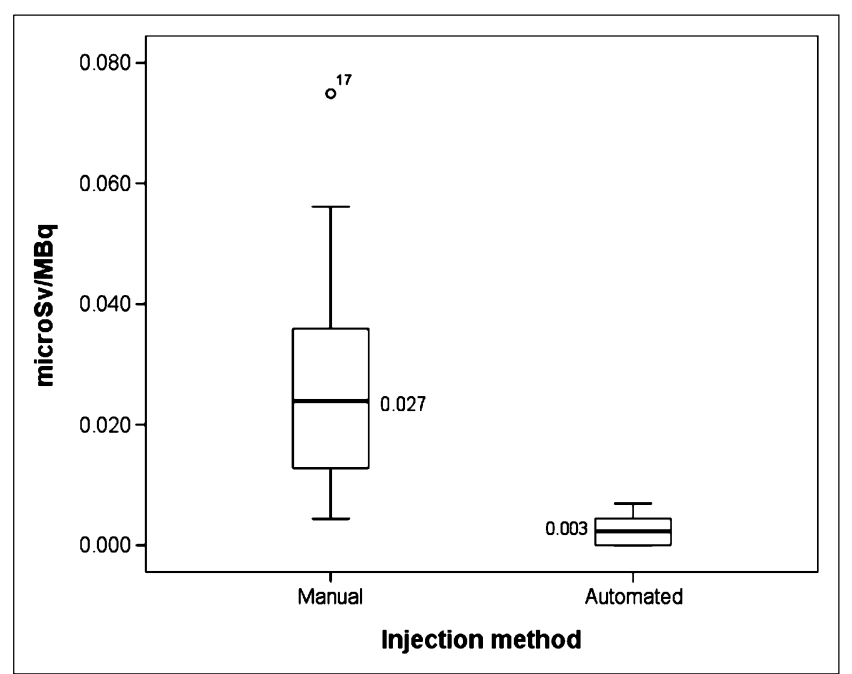

FIGURE 3. Extremity doses yielded by manual and automated injection methods.

The mean differences were statistically significant by the Mann-Whitney $U$ test $(P<0.001)$ (Tables 3 and 4$)$.

\section{Vial Change}

In 34 loading procedures, mean vial radioactivity was $20,174.3 \pm 1,298.9 \mathrm{MBq}(545.3 \pm 35.1 \mathrm{mCi})$. In 3 unloading procedures, mean vial radioactivity was $382.3 \pm 149.5$ $\mathrm{MBq}(10.3 \pm 4.0 \mathrm{mCi})$. The changing of bulk ${ }^{18} \mathrm{~F}-\mathrm{FDG}$ vials added a mean extremity dose per vial change of $0.89 \pm 1.3 \mu \mathrm{Sv}(0.09 \pm 0.1 \mathrm{mrem})$ and a mean body dose per vial change of $0.47 \pm 2.0 \mu \mathrm{Sv}(0.05 \pm 0.2 \mathrm{mrem})$.

\section{DISCUSSION}

In deciding whether to use or purchase an automated radiopharmaceutical dosing device, one needs to consider several factors, including cost, reliability, service availability, training requirements, and, most important, the potential

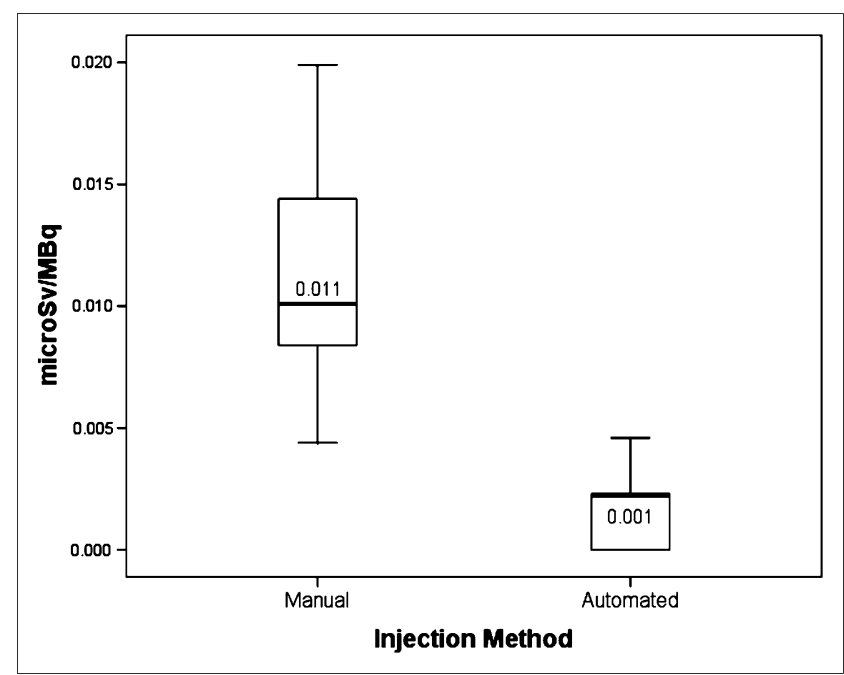

FIGURE 4. Body doses yielded by manual and automated injection methods.
TABLE 3

Extremity Dose ( $\mu \mathrm{Sv} / \mathrm{MBq})$

\begin{tabular}{lccccc}
\hline Injection method & Mean & $N$ & SD & Minimum & Maximum \\
\hline Manual & 0.0265 & 25 & 0.017 & 0.004 & 0.075 \\
Automated & 0.0025 & 34 & 0.002 & 0.000 & 0.007 \\
Total & & 59 & & & \\
\hline
\end{tabular}

dose savings for patients and staff. This study specifically focused on occupational dose burdens, yet our results also confirmed that the automated injections delivered a more precise and lower administered radiopharmaceutical dose, which in turn potentially provides a lower and more uniform effective patient dose. With the automated infusion device, there was an approximately 10-fold reduction in occupational extremity and body dose values. Furthermore, the additional exposures from loading and unloading the bulk vials of ${ }^{18}$ F-FDG contributed relatively minimal additional radiation exposure to the staff.

To illustrate the importance of these dose reductions, one could extrapolate the reductions per unit dose to a quarterly dose report. A simple hypothetical example assumes that 5 patients per day are injected by the same technologist over a calendar quarter comprising 60 workdays. The resultant occupational body dose from a $370-\mathrm{MBq}(10.0-\mathrm{mCi})$ injection of ${ }^{18} \mathrm{~F}$ radiotracer would be $0.001 \mu \mathrm{Sv} / \mathrm{MBq} \times 370 \mathrm{MBq} /$ patient $\times 5$ patients $/ \mathrm{d} \times 60 \mathrm{~d} /$ quarter $=111.0 \mu \mathrm{Sv}(11.1$ mrem) when the automated device is used. By contrast, with manual injection technique, the whole-body dose would be $0.011 \mu \mathrm{Sv} / \mathrm{MBq} \times 370 \mathrm{MBq} /$ patient $\times 5$ patients $/ \mathrm{d} \times 60$ $\mathrm{d} /$ quarter $=1,221 \mu \mathrm{Sv}$ (122.1 mrem). This closely approximates our institution's ALARA (as low as reasonably achievable) I value of $10 \%$ of the quarterly maximum permissible doses of $1.25 \mathrm{mSv}$ (125 mrem) for workers in the United States (the annual deep dose equivalent limit for radiation workers in the United States currently remains at 50.0 $\mathrm{mSv}[5,000 \mathrm{mrem}](11))$.

This study had several limitations. First, whereas both the ion chamber and the electronic dosimeters optimally perform at the $0.511-\mathrm{MeV}$ range, we did not apply exact sensitivity corrections for each device. Furthermore, the lower limit of detection of the electronic dosimeter is 1.0 $\mu \mathrm{Sv}(100 \mu \mathrm{rem}=0.1 \mathrm{mrem})$. It is probably unlikely, though not completely established, that doses less than this would be meaningful. Second, a single automated injection device was evaluated, although several commercial and

TABLE 4

Body/Trunk Dose ( $\mu \mathrm{Sv} / \mathrm{MBq})$

\begin{tabular}{lccccc}
\hline Injection method & Mean & $N$ & SD & Minimum & Maximum \\
\hline Manual & 0.0111 & 25 & 0.005 & 0.004 & 0.020 \\
Automated & 0.0014 & 33 & 0.002 & 0.000 & 0.005 \\
Total & & 58 & & & \\
\hline
\end{tabular}


in-house custom-designed devices may be available to others as possible alternatives. Finally, the participating technologists had used the automated infusion device for 10-11 mo before this study; that is, because the learning curve for using this device had been well established, lengthy vial replacement task times, troubleshooting of problems, or injection mishaps were rarely if ever observed. One might anticipate longer radiation exposure times for certain tasks from novice users of the device. We also evaluated the technologist group as a single heterogeneous cohort and did not separate exposure values by education, training, or vial-handling technique. Future investigations could further stratify results.

\section{CONCLUSION}

The use of the described shielded automatic infusion device in a clinical PET setting resulted in an approximately 10-fold decrease in staff extremity and body doses during the administration of ${ }^{18} \mathrm{~F}$-labeled radiopharmaceuticals. Loading and unloading bulk vials of radiotracer did not significantly offset these dose savings.

\section{ACKNOWLEDGMENTS}

We thank and acknowledge the nuclear medicine technical staff of Brigham and Women's Hospital who graciously and actively served as participants in this project. Helpful suggestions were also received by anonymous reviewers. The authors claim no relationships or existing conflicts of interest with any of the manufacturers or commercial interests mentioned in this paper.

\section{REFERENCES}

1. Biran T, Weininger J, Malchi S, et al. Measurement of occupational exposure for a technologist performing ${ }^{18}$ F-FDG PET scans. Health Phys. 2004;87:539-544.

2. Roberts FO, Gunawardana DH, Pathmaraj K, et al. Radiation dose to PET technologists and strategies to lower occupational exposure. J Nucl Med Technol. 2005;33:44-47.

3. Schleipman AR, Castronovo FP, Di Carli MF, Dorbala S. Occupational radiation dose associated with ${ }^{82} \mathrm{Rb}$ myocardial perfusion positron emission tomography (PET) imaging. J Nucl Cardiol. 2006;13:378-384.

4. McElroy NL. Worker dose analysis based on real time dosimetry. Health Phys. 1998;74:608-609.

5. Gomez-Palacios M, Terron JA, Dominguez P, et al. Radiation doses in the surroundings of patients undergoing nuclear medicine diagnostic studies. Health Phys. 2005;89(suppl):S27-S34.

6. Lundberg TM, Gray PJ, Bartlett ML. Measuring and minimizing the radiation dose to nuclear medicine technologists. J Nucl Med Technol. 2002;30:25-30.

7. Chiesa C, De Sanctis V, Crippa F, et al. Radiation dose to technicians per nuclear medicine procedure: comparison between technetium-99m, gallium-67, and iodine131 radiotracers and fluorine-18 fluorodeoxyglucose. Eur J Nucl Med. 1997;24: 1380-1389.

8. Guillet B, Quentin P, Waultier S, et al. Technologist radiation exposure in routine clinical practice with ${ }^{18}$ F-FDG PET. J Nucl Med Technol. 2005;33:175-179.

9. Covens P, Berus D, Vanhavere F, Caveliers V. The introduction of automated dispensing and injection during PET procedures: a step in the optimisation of extremity doses and whole-body doses of nuclear medicine staff. Radiat Prot Dosimetry. 2010;140:250-258.

10. Berthold T, Weber B, Buck A. An automatic ${ }^{18} \mathrm{~F}-\mathrm{FDG}$ infusion system in clinical PET/CT. Paper presented at: RSNA 2009: Proceedings of the 95th Scientific Assembly and Annual Meeting of the Radiologic Society of North America; November 29-December 4, 2009; Chicago, IL. Available at: http://rsna2009. rsna.org/search/search.cfm?action=add\&filter=Author\&value=68224. Accessed September 19, 2012.

11. Standards for protection against radiation. Fed Regist. 1991;56:23396. Codified at 10 CFR $\$ 20.1201$. 